\title{
Computed tomography study of the fetal development of the dairy cow stomach complex
}

\author{
S. Al Masri, ${ }^{11}$ R. Reincke, ${ }^{*}$ H. Huenigen, ${ }^{*}$ O. Gemeinhardt, $†$ K. C. Richardson, $\ddagger$ and J. Plendl* \\ *Department of Veterinary Medicine, Institute of Veterinary Anatomy, Freie Universität Berlin, 14195 Berlin, Germany \\ †Charité-Universitätsmedizin Berlin, Humboldt-Universität zu Berlin, and Department of Radiology, Berlin Institute of Health, \\ 12203 Berlin, Germany \\ $\ddagger$ School of Veterinary and Life Sciences, College of Veterinary Medicine, Murdoch University, Murdoch 6150, Western Australia
}

\section{ABSTRACT}

In the fetal development of animals, critical physiological and anatomical events influence the long-term health and performance of the offspring. To identify the critical growth phases of the fetal bovine stomach, we used computed tomography imaging on 30 German Holstein fetuses to examine the fetal bovine stomach in situ. Computed tomography allows the study of diverse parameters such as the volume of the stomach chambers in situ without the need for sophisticated filling preparation techniques. The absolute volume, relative volume, and monthly volume increase of each stomach chamber were determined. Computed tomography was a reliable method for in situ examination of the fetal bovine stomach complex from the third month of gestation onward. It was able to detect an abnormal position of the abomasum in 2 fetuses. The crown-rump length of the fetuses studied ranged from 9.5 to $89 \mathrm{~cm}$ (from 2.2 to 8.3 mo of gestation). Over this timeline, the changes in the relative volumes of the ruminoreticulum and abomasum were inversely related. Until mo 5 of gestation, the relative volume of the ruminoreticulum increased steadily, whereas that of the abomasum decreased. Thereafter, the relative volume of the ruminoreticulum became gradually smaller, and that of the abomasum became larger; by mo 8, the abomasum was larger than the ruminoreticulum. All stomach chambers had large increases in volume over the gestation period and we observed differences in development patterns and volume changes of the individual stomach chambers over this period. The largest monthly volume increase of the stomach complex was between mo 4 and 5 of gestation. In this period, the volume of the ruminoreticulum increased 43.8 times, that of the omasum 38.9 times, and that of the abomasum 30.03 times. Between mo 5 and 6 of gestation, the abomasum had another growth spurt,

Received July 17, 2017.

Accepted October 26, 2017.

${ }^{1}$ Corresponding author: Salah.AlMasri@fu-berlin.de with a monthly volume increase of 10.4 times. These 2 time points in the gestation period may be critical phases of fetal development that should be considered in the management of pregnant cattle.

Key words: cow stomach, intrauterine programming, fetal development, abomasum

\section{INTRODUCTION}

The evolution of the ruminant stomach complex occurred about 50 million years ago and was the result of adaptive processes for the efficient use of cellulosebased diets (Langer, 1988; Hofmann, 1989). This has resulted in modern ruminants having a suite of complex morphological changes that occur both prenatally and postnatally to allow the neonate to effectively and efficiently digest milk as its primary diet and then to transition to a plant-based diet.

During fetal development of the ruminant stomach, complex growth and differentiation processes result in a stomach having 4 functional compartments: rumen, reticulum, omasum, and abomasum. After birth, the initial dependence on milk and subsequent transition to a plant-based diet is critical. During the transition period of 2 to $3 \mathrm{mo}$, the forestomachs (rumen, reticulum, omasum) must develop both morphologically and physiologically to undertake their roles in the microbial fermentation of plant material after weaning (Silper et al., 2014).

Recent studies have shown that metabolic programming of calves postpartum plays a major role in their lifetime performance and productivity (Moallem et al., 2010; Soberon et al., 2012; Soberon and Van Amburgh, 2013). A meta-analysis of 12 neonatal studies in cattle showed that long-term milk productivity was promoted by increased nutrient intake from milk or milk replacer during the preweaning period (Soberon and Van Amburgh, 2013). Intrauterine development is at least as important as extrauterine development in the subsequent health and performance in later life (Bell, 2006; Funston et al., 2010). Intrauterine programming de- 
scribes the process by which stimuli at critical phases of fetal development during gestation create long-lasting changes in tissue structure and function (Fowden et al., 2006; Opsomer et al., 2016). The timing, duration, and exact nature of the stimuli are crucial determinants of the pattern and extent of intrauterine growth and of specific physiological outcomes (Fowden et al., 2006).

By the end of the bovine embryonic period on d 44 of gestation, the different stomach compartments - ruminoreticulum, omasum, and abomasum - can be distinguished and have an independent shape (Vivo et al., 1990). In a 110-mm-long (mo 3 ) bovine fetus, the shape and position of the stomach is very close to its final appearance (Schummer, 1932). In the subsequent fetal period, the stomach chambers grow in size and their proportions change. The development of the fetal bovine stomach has been described in several previous studies (Becker et al., 1951; Wardrop and Coombe, 1961; Kano et al., 1981; Schnorr and Kressin, 2011). However, those studies were mainly observations of formalin-fixed stomachs or used filling preparation techniques (Kano et al., 1981). Recently, computed tomography (CT) has been used to demonstrate the in situ development of the bovine stomach (Flor et al., 2012). Computed tomography scanning generates sets of data that can be operated to demonstrate various organs and tissues based on their ability to absorb the x-ray beam, and allows these data to be reformatted in various planes or as volumetric (3-dimensional, 3D) visualizations of structures. The post-processing methods facilitate qualitative and quantitative evaluation of structures, including determinations of volume, area, or distance. Finally, CT allows the study of diverse parameters such as the volume of the stomach chambers without the need for complex filling preparation techniques.

We hypothesized that the stomach compartments of fetal cattle develop at different rates during gestation and that critical development phases exist that should be considered. The aim of the present study was to investigate the pattern of development of the bovine stomach of German Holstein fetuses using CT, focusing on volumetric and topographic changes of the stomach complex from mo 3 to 9 of gestation.

\section{MATERIALS AND METHODS}

\section{Animals}

Thirty bovine fetuses (16 female and 14 male; Table 1) obtained from a slaughterhouse (Teterower Fleisch GmbH, Teterow, Germany) were used in this study. The fetuses were taken from German Holstein cows slaughtered between October 2011 and June 2013. The history of the slaughtered cows was unknown and there were no multiple fetuses. Approximately $30 \mathrm{~min}$ after each cow had been killed, its fetus was collected and sex was determined immediately.

The crown-rump length (CRL) of each fetal calf was measured with the fetus in lateral recumbency. Using a measuring tape, the CRL was measured as a straight line from the foramen occipital magnum (opisthion) to the first caudal vertebra. The age of the fetuses (mo) was estimated according to Michel (1995) where gestational month $=\sqrt{ }(\mathrm{CRL}+1)-1$. The BW of fetuses less than 2,000 g was measured using an electronic scale (Univers; Petermann, Dombühl, Germany). Heavier animals were weighed using a separate electronic scale (PJ 3600 DeltaRange; Mettler, Gießen, Germany). Then, fetuses were transported immediately within a cool box to the CT room.

\section{CT}

Computed tomography of the abdomen was performed to evaluate the morphology and morphometry of the stomach complex. The CT scan was done using a third-generation 16-slice scanner (Phillips Brilliance, Phillips Healthcare, Hamburg, Germany). To prevent deformation of stomach compartments by gravitational effects, the fetuses were positioned on the table in a supine position and held in place using foam wedges and hook-and-loop fastening straps. They were scanned using standardized scan parameters (voltage $120 \mathrm{kV}$, $200 \mathrm{~mA}$; collimated slice thickness: $16 \times 0.75 \mathrm{~mm}$; increment: $1.5 \mathrm{~mm}$; pitch: 0.938).

For volumetric determinations, 2-mm images were reconstructed without overlap. Because the junction between the rumen and reticulum could not be identified reliably on the $\mathrm{CT}$ images, the 2 compartments were considered a single functional unit, the ruminoreticulum. Basic image analysis was performed and the volume of each stomach chamber (ruminoreticulum, omasum, and abomasum) was calculated using Amira 5.4 software (FEI Visualization Sciences Group, Mérignac, France). A manual segmentation technique was used to separate each stomach chamber from the surrounding context. The image segmentation of the stomach chamber was carried out by hand in the axial plane, along their inner contour at the junction of the soft tissue and the fluid filled lumen of each stomach compartment (Figure 1, panels A, B, and C). The segmentation process was controlled along all 3 view axes. To validate the method, the segmentation process was performed twice at different times by the same person for all 30 fetuses and the mean value taken.

The position of the stomach chamber was defined in all 3 axes and the craniocaudal extent of the ruminoreticulum, omasum, and abomasum was determined 
based on the adjacent vertebrae (Figure 1, panels A, $\mathrm{B}$, and $\mathrm{C})$.

\section{Statistics and Data Analysis}

Because of the descriptive nature of our study, the data of the stomach chamber volumes were analyzed using descriptive statistics. According to the calculated gestational age, the fetuses were allocated to monthly intervals (Table 1). The monthly volume increase factor of each stomach chamber was calculated as follows: monthly volume increase $=$ (value of the current month - value of the previous month)/value of the previous month. Data are reported as mean value \pm standard deviation for continuous variables.

To estimate the relationship between BW and CRL during gestation, fetal BW data were analyzed by least squares regression method with CRL as the independent variable. The regression equation with the highest significant regression or with the highest coefficient of determination $\left(\mathrm{R}^{2}\right)$ was obtained. Fetal weight data were also analyzed for effects of sex of fetus using a multiple linear regression model, with CRL and sex as independent variables. Statistical analyses were performed using SPSS for Windows software (version 20; SPSS/IBM Corp., Chicago, IL). Data visualization was done using Excel 2013 (Microsoft Corp., Redmond, WA), and the JMP Pro 13 statistical package (SAS Institute Inc., Cary, NC). A $P$-value $<0.05$ was considered significant.

\section{RESULTS AND DISCUSSION}

\section{Background}

Many individual tissues and whole-organ systems are programmed in utero, with diverse consequences for their physiological function later in life (Fowden et al., 2006; Opsomer et al., 2016). In precocial species, such as cattle, that are physiologically relatively mature at birth, their physiological characteristics are programmed in utero and are completed shortly after

Table 1. Overview of each bovine fetus studied

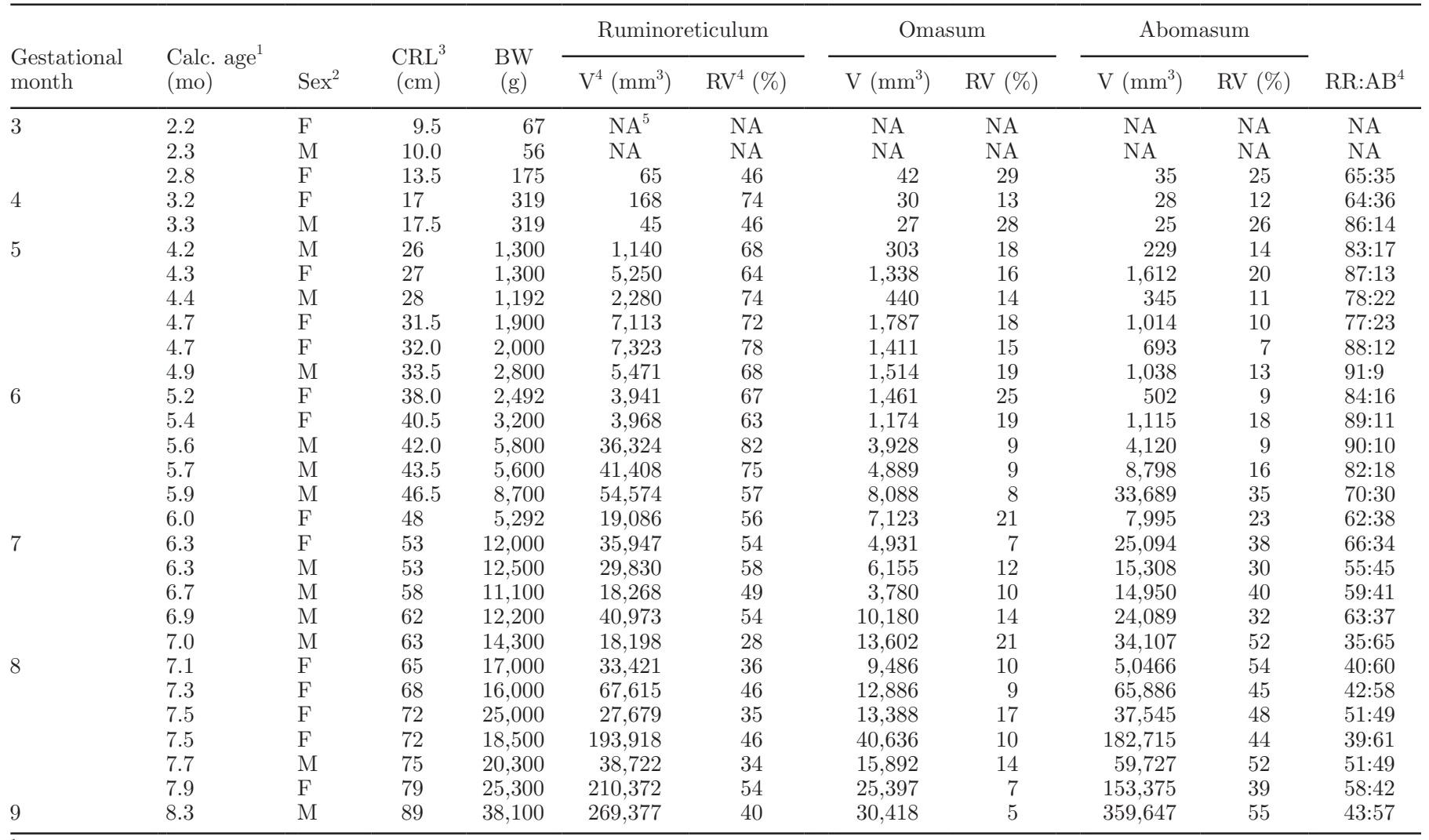

${ }^{1}$ Calculated age (mo).

${ }^{2} \mathrm{~F}=$ female; $\mathrm{M}=$ male.

${ }^{3}$ Crown-rump length.

${ }^{4} \mathrm{~V}=$ volume; $\mathrm{RV}=$ relative volume; $\mathrm{RR}: \mathrm{AB}=$ ratio of ruminoreticulum to abomasum.

${ }^{5}$ Not applicable. 

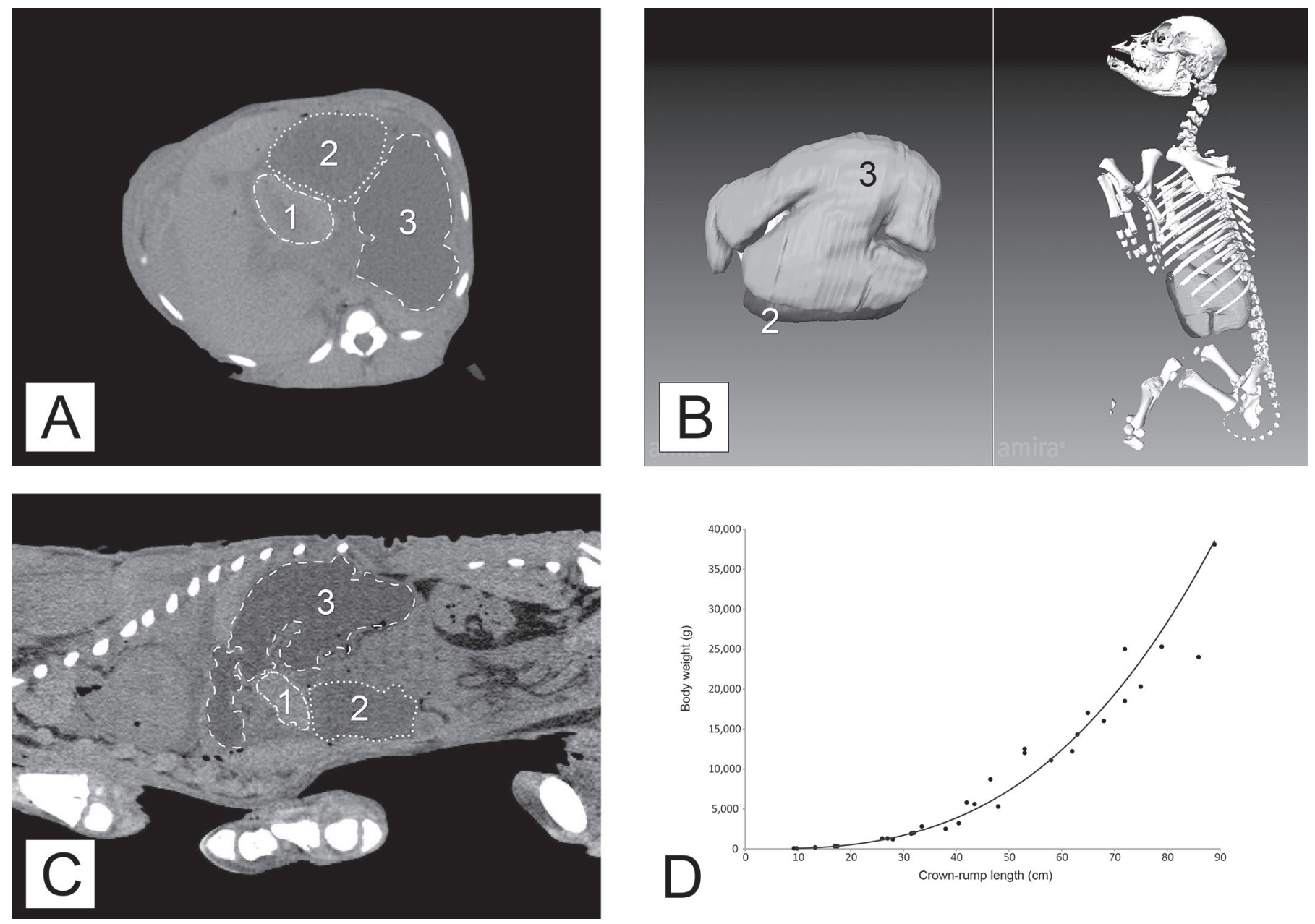

Figure 1. Segmentation of the stomach of male bovine fetus in month 8 , where $1=$ omasum, $2=$ abomasum, $3=$ ruminoreticulum. Panels $\mathrm{A}$ and $\mathrm{C}$ are computed tomography $(\mathrm{CT})$ images and panel $\mathrm{B}$ is a 3-dimensional reconstruction of the CT scans. Panel D shows the regression curve of BW and crown-rump length during the entire examination period.

birth (Fowden et al., 1998). Consequently, intrauterine programming appears essential for the health and longterm productivity of these species. Furthermore, some adult disorders are thought to originate through fetal responses to intrauterine challenges such as undernutrition or placental insufficiency (Opsomer et al., 2016). For example, insufficient placental blood supply can affect fetal growth and result in permanent maladaptations in endocrine and metabolic processes (Hales and Barker, 1992, 2001). In addition, the period of gestation during which intrauterine programming occurs determines which cell types or organs are most influenced (Bertram and Hanson, 2001; Fowden et al., 2006). Optimizing stomach development by birth in dairy cows should positively influence subsequent health and performance throughout their productive life. Nevertheless, the critical prenatal growth periods of the stomach complex are still poorly understood.

\section{Gestational Age and BW}

The CRL ranged from 9.5 to $89 \mathrm{~cm}$ (Table 1) for fetuses with calculated gestational ages ranging from 2.2 to 8.3 mo. Overall, monthly fetal BW increased continuously throughout gestation. In this study, the youngest fetus $(2.2 \mathrm{mo})$ had a BW of $67 \mathrm{~g}$ and the oldest $(8.3 \mathrm{mo}) 38,100 \mathrm{~g}$ (Table 1). Our data agree with earlier studies on the relationships between BW and age as reported by Habermehl (1975) and Rüsse and Grunert (1993). The maximum monthly increase in BW occurred over mo 5 of gestation (Figure 2A), where the monthly increase factor was 4.48. The relationship between $\mathrm{BW}$ and $\mathrm{CRL}$ was as follows: $\mathrm{BW}=0.09 \times$ $\mathrm{CRL}^{2.88} ; \mathrm{R}^{2}=0.99$ (Figure 1D). Closer analysis of the data shows that over the first half of pregnancy (i.e., up to a CRL of $30 \mathrm{~cm}$, equivalent to a gestational age of $4.56 \mathrm{mo}$ ), the BW/CRL relationship increased expo- 
nentially: y $(\mathrm{BW})=14.8 \mathrm{e}^{0.167(\mathrm{CRL})} ; \mathrm{R}^{2}=0.97$. Earlier studies reported similar results (Lyne, 1960; Eley et al., 1978; Prior and Laster, 1979; Szuba et al., 1988). In the second half of pregnancy, we found a linear correlation of BW and CRL: y $(\mathrm{BW})=517.1 \times(\mathrm{CRL})-16,479$; $\mathrm{R}^{2}=0.91$; this is consistent with the findings of Bell et al. (1995).

The regression analysis indicated no statistically significant difference in BW between male and female fetuses over the complete observation period. Szuba et al. (1988) also found no statistically significant differences between male and female Holstein cattle fetuses. In contrast, Witt et al. (1964) and Dhakal et al. (2013) found that male Holstein calves were 2 and $2.3 \mathrm{~kg}$ (Holland and Odde, 1992) heavier, respectively, than females at birth. The longer gestation period in male animals was stated to be the reason for the greater BW at birth.

\section{Absolute Stomach Volume}

To our knowledge, there are no previous reports on the absolute volume of the prenatal bovine stomach in situ. Only in studies on postnatal development was the absolute volume of the stomach compartments reported (Warner et al., 1956; Godfrey, 1961; Tamate et al., 1962). Here, Warner et al. (1956) and Tamate et al. (1962) determined the volume of the bovine stomach by the filling the isolated compartments with water. However, in other studies, the weights of the individual stomach compartments were determined to estimate the size of the stomach (Becker et al., 1951; Godfrey, 1961).

We used a noninvasive technique to determine the volume of the stomach compartments. The volume of each stomach chamber was calculated as an absolute volume $\left(\mathrm{mm}^{3}\right)$ and as a percentage of the total stomach complex volume (Table 1). Unfortunately, in the smallest (CRL 9.5 and $10 \mathrm{~cm}$ ), and thus youngest (2.2 and 2.3 mo), fetuses, the borders between the different stomach chambers were unclear on the CT images because of the lack of intra-abdominal fat. Thus, segmentation of their stomach chambers was not possible and we could not calculate volumes for these fetuses. Examination of the older fetuses showed that all stomach chambers had large increases in volume over the gestation period and that the development patterns and volume changes of the ruminoreticulum, omasum, and abomasum differed over this timeline (Table 2, Figure 2A). Based on monthly volume changes, the largest volume increases occur in the transition from mo 4 to mo 5 of pregnancy (ruminoreticulum $=43.79$ times, abomasum $=30.03$ times, omasum $=38.85$ times). In the same period, the monthly increase factor of the BW was only 4.48.
In addition, during the transition from mo 5 to mo 6 of pregnancy, the abomasum had a second growth spurt (monthly volume increase $=10.4$ times) and the ruminoreticulum increased 4.57 times and the omasum 2.93 times (Figure 2A). This growth spurt may be a critical phase for fetal programming. Interestingly, stomach compartment volumes increase steadily and at a relatively slow rate from mo 6 onward. Even so, the absolute volume changes over the final month of gestation were large.

\section{Relative Stomach Volume}

In mo 3 of pregnancy, the ruminoreticulum was the largest compartment of the stomach complex (Table 2 ). Subsequently, the relative volume of the ruminoreticulum increased steadily, reaching a maximum in mo 5 (Figure 2B). After that, the percentage of the ruminoreticulum dropped until the beginning of mo 9 , when it was the second-largest compartment of the stomach complex.

The abomasum was the smallest compartment of the stomach complex in mo 3 of gestation. Over the next 2 mo, the relative volume of the abomasum decreased steadily to reach its minimum in mo 5 (Figure 2B). From then until the end of the gestation, the percentage of the abomasum increased markedly and reached its maximum at mo 9 of gestation.

Furthermore, the developmental patterns of the ruminoreticulum and the abomasum were inverse. This confirms the results of Kano et al. (1981), who used a filling preparation technique where they injected a synthetic polyester resin to determine the volumes of individual stomach compartments. In the present study, the bovine stomach compartments were, for the first time, quantified and visualized by CT. We found that at mo 3 and 4 of gestation, the ruminoreticulum was notably larger than the abomasum (Tables 1 and 2 ). Thereafter, the difference between the 2 chambers increased and the ratio reached a maximum during mo 5 of gestation, averaging 85:15. In mo 6 of gestation, the difference between the 2 chambers again decreased. At mo 7 of gestation, the abomasum had undergone a greater volume increase and the ratio was 56:44. From mo 8 onward, the ratio continued to change as the abomasum became larger than the ruminoreticulum (Table 2). In Kano et al. (1981), dynamic changes occurred along a similar timeline, ending with the abomasal volume at birth being twice that of the rumen. Other authors who investigated the proportions of the fetal stomach compartments simply determined the weight of each compartment (Becker et al., 1951; Johnson et al., 1996). They found that the ruminoreticulum was heavier than the abomasum until mo 6 

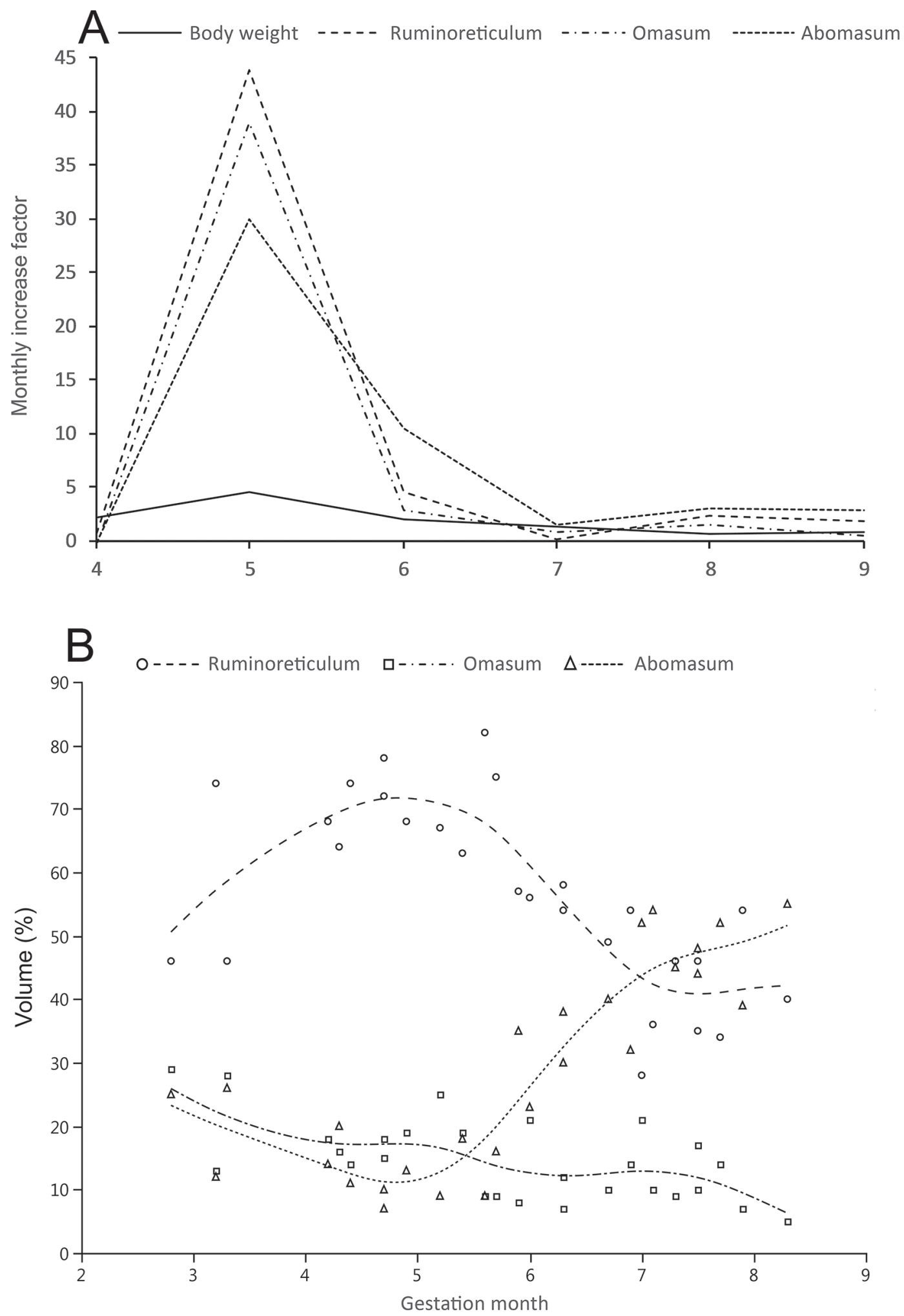

Figure 2. (A) Monthly BW increase of the fetuses and the monthly absolute volume increase of each stomach compartment. (B) Trendlines of the changes in the relative volume $(\%)$ of each stomach compartment from mo 3 to 9 of gestation. Dots represent each individual value for each stomach compartment. 


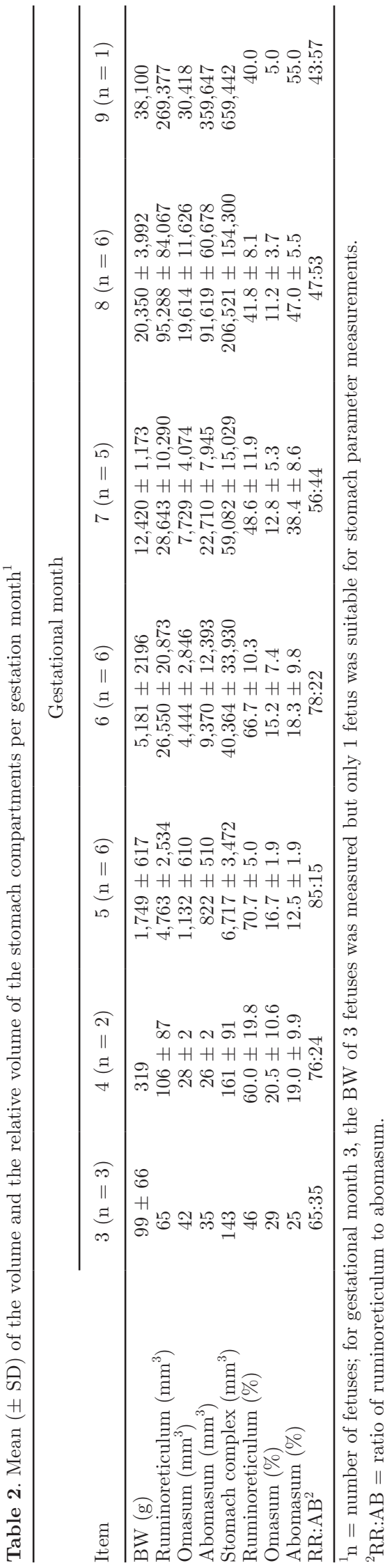

(Becker et al., 1951) or mo 7 (Johnson et al., 1996); thereafter, abomasal weight increased noticeably until birth. According to Becker et al. (1951) and Johnson et al. (1996), the inverse development of the ruminoreticulum and abomasum is necessary for optimal abomasal function immediately after birth, because at that time the forestomachs are not involved in milk digestion. However, Flor et al. (2012) reported casein fragments in the rumen of newborn calves because the reticular groove bypass of the forestomach chambers is incomplete. They suggest that this milk spillage into the rumen is physiological and even essential for the microbial colonization of the ruminoreticulum.

In mo 3 of gestation, the omasum was the second largest gastric compartment. As gestation continued, the percentage of the omasum decreased slightly until mo 8 of gestation, when there was a rapid decrease to $5 \%$ of the total volume in mo 9 of gestation. From mo 6 to mo 9 , the omasum was the smallest compartment of the stomach complex (Figure 2B). The omasum is almost completely developed over the last third of pregnancy and changes only slightly after birth (Johnson et al., 1996; Flor et al., 2012).

\section{The Stomach In Situ}

Over the entire study period, the ruminoreticulum extended craniocaudally within the abdominal cavity and had the greatest length of all stomach compartments (Figures 3 and 4 ). At the beginning of mo 3, it extended from the level of the 7 th thoracic vertebra to the level of the 4th lumbar vertebra. In mo 4, the ruminoreticulum extended from the 7th thoracic vertebra to the 5th lumbar vertebra. From mo 7 of gestation, the ruminoreticulum was found consistently between the 9th thoracic and the 3rd lumbar vertebra.

The omasum occupied the smallest craniocaudal position in the abdominal cavity. It retained a spherical shape and lay mostly in the intrathoracic part of the abdomen (Figures 3 and 4). At the beginning of mo 3, the omasum lay between the 10th thoracic vertebra and the 13th thoracic or 1st lumbar vertebra. Its maximal extension, from the 7 th or 8 th thoracic vertebrae to the 1st lumbar vertebra, occurred in mo 4 of gestation. From mo 6, the omasum lay predominantly in the intrathoracic part of the abdominal cavity between the 9 th and 13th thoracic vertebrae. At the beginning of mo 9, the omasum extended to the 2nd lumbar vertebra.

Throughout the study period, the abomasum was longer than the omasum but shorter than the ruminoreticulum (Figures 3 and 4). At the beginning of mo 3 of gestation, it extended from 10th/11th thoracic vertebrae to the 1 st/2nd lumbar vertebrae. In mo 4 , the abomasum lay between the 8th thoracic vertebra and 

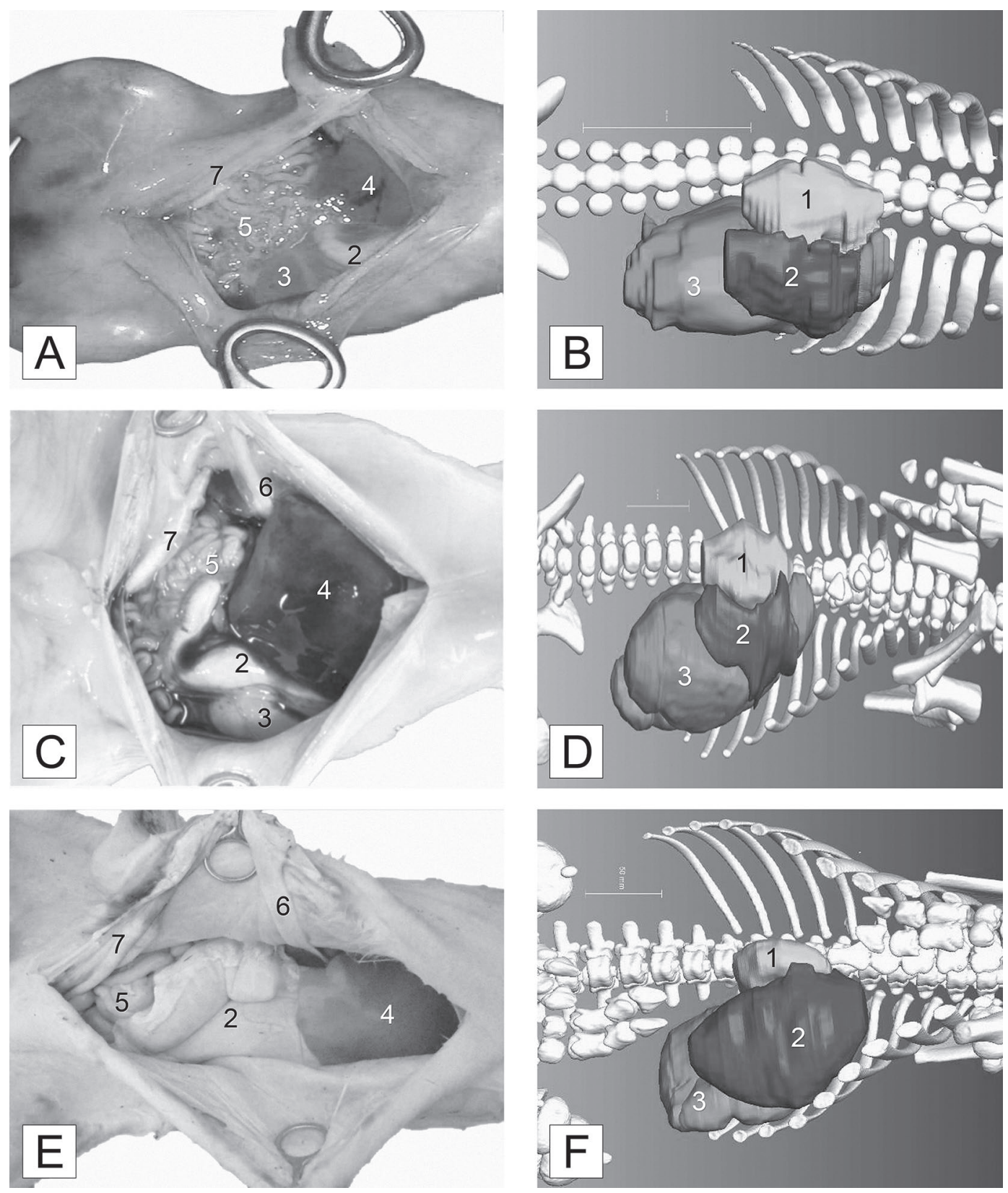

Figure 3. Ventral view of representative bovine fetuses. Panels A, C, and E are gross specimens of the abdominal cavity in situ; panels B, D, and $\mathrm{F}$ are 3-dimensional reconstructs of the computed tomography scans to show the relationship of the stomach compartments to the adjacent skeletal elements. A and B: female fetus in mo 3 of gestation with crown-rump length (CRL) of $17 \mathrm{~cm}$; C and D: male fetus in mo 5 of gestation with CRL of $33.5 \mathrm{~cm}$; E and F: female fetus in mo 8 of gestation with CRL of $79 \mathrm{~cm}$. All panels: $1=$ omasum, $2=$ abomasum, $3=$ rumen ventral sac, $4=$ left hepatic lobe, $5=$ intestine, $6=$ umbilical vein, $7=$ umbilical artery.

the 1st/2nd lumbar vertebrae. However, during mo 5, it only extended between the 9th thoracic and the 1st lumbar vertebra. In mo 6 , the abomasum extended from the 10th thoracic to the 3rd lumbar vertebra. Thereafter, there was no constant position of the abomasum. This may be due to the corresponding greater abomasal volume, which was increasing at this time, and to the loose fixation of the abomasum by its relatively long mesentery, allowing the ruminoreticulum to lie in direct contact with the dorsal abdominal wall. Nevertheless, the abomasum was always partially intrathoracic due to the short bile duct connecting the liver to the proximal part of the duodenum. The dynamic relationship of the growth rates of the vertebral skeleton and the stomach could be a factor in the variable positions of stomach compartments. 
In most of the fetuses studied, the abomasum was located on the ventral wall of the abdomen on the right side of the ruminoreticulum. However in 2 fetuses - a male fetus in mo 7 of gestation $(\mathrm{CRL}=63 \mathrm{~cm})$ and a female fetus in mo $9(\mathrm{CRL}=89 \mathrm{~cm})$ - the abomasum was displaced to the left side of the ruminoreticulum and located between the rumen and lateral abdominal wall (Figure 5). At the same time, the ruminoreticulum and the omasum were displaced to the right and lay almost in the middle of the abdominal cavity. This abnormal position of the stomach chambers in the abdomen, called left-sided abomasal displacement, is a hereditary disorder that is relatively common in dairy breeds but less common in beef breeds (Roussel et al., 2000; Zerbin et al., 2015; Oman et al., 2016). The prevalence of leftsided abomasal displacement in calves is poorly known;
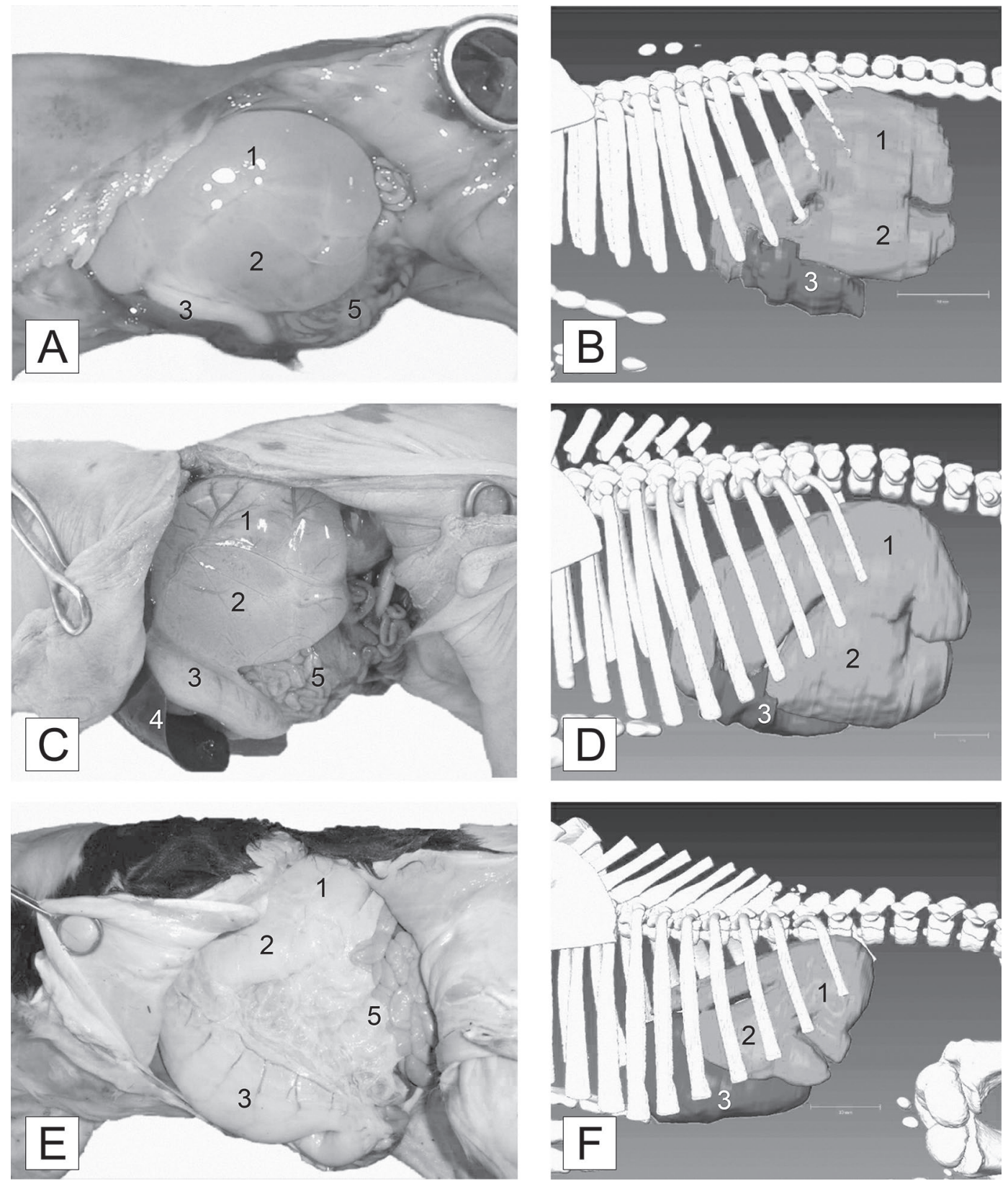

Figure 4. Left lateral view of representative bovine fetuses. Panels A, C, and E are gross specimens of the abdominal cavity in situ; panels $\mathrm{B}, \mathrm{D}$, and $\mathrm{F}$ are 3-dimensional reconstructs of the computed tomography scans to show the relationship of the stomach compartments to the adjacent skeletal elements. $\mathrm{A}$ and $\mathrm{B}$ : female fetus in mo 3 of gestation with crown-rump length (CRL) of $17 \mathrm{~cm}$; C and D: male fetus in mo 5 of gestation with CRL of $33.5 \mathrm{~cm}$; E and F: female fetus in mo 8 of gestation with CRL of $79 \mathrm{~cm}$. All panels: $1=$ rumen dorsal sac, $2=$ rumen ventral sac, 3 = abomasum, $4=$ left hepatic lobe, $5=$ intestine. 

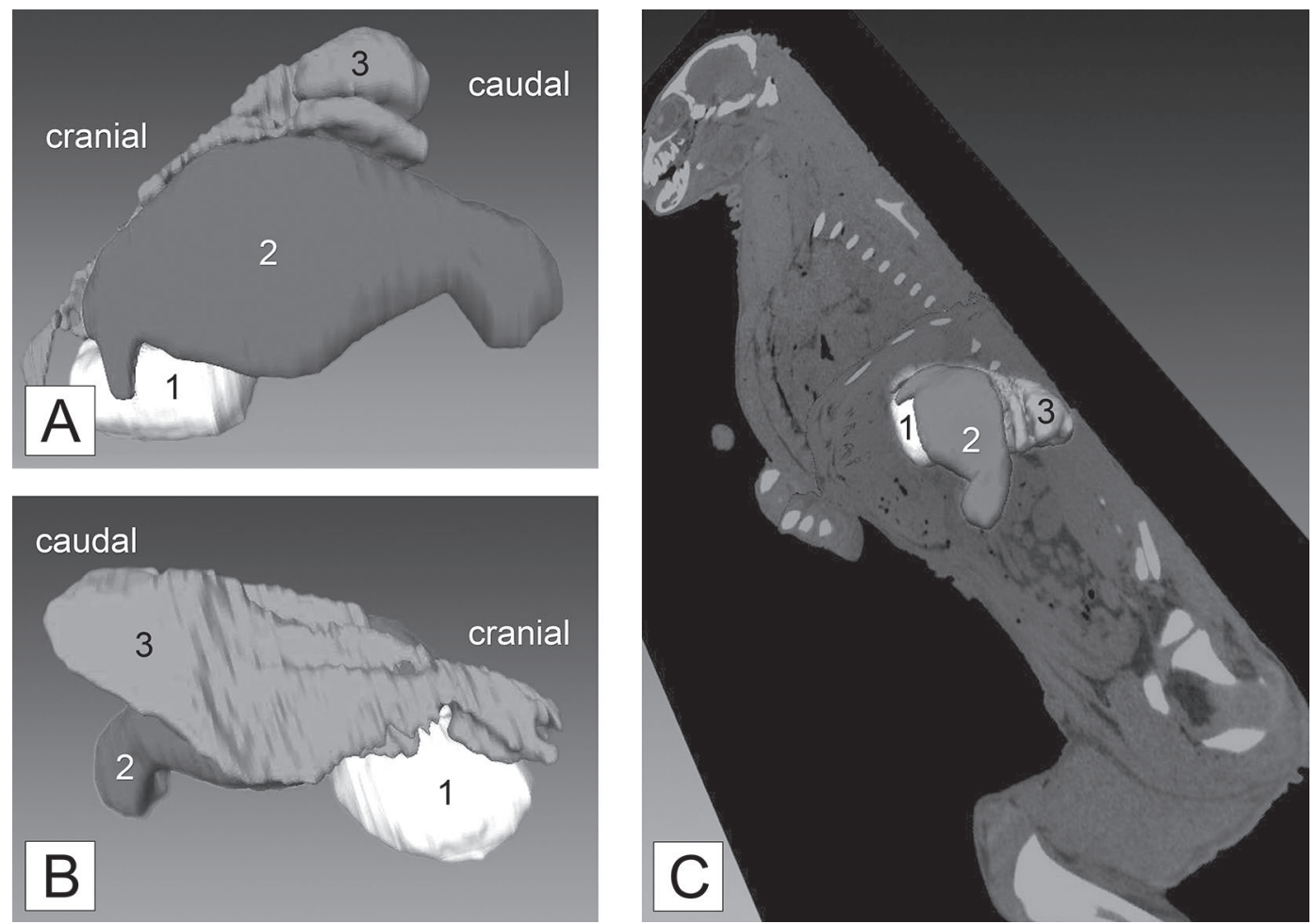

Figure 5. Bovine male fetus in mo 7 of gestation with a crown-rump length of $63 \mathrm{~cm}$ : (A) 3-dimensional (3D) stomach view from left, (B) $3 \mathrm{D}$ stomach view from right, and $(\mathrm{C})$ sagittal computed tomography plane with $3 \mathrm{D}$ visualization of the stomach from the left side. $1=$ omasum, 2 = abomasum, 3 = ruminoreticulum.

however, some clinical cases have been reported, for example, in two 4-wk-old calves (Mueller et al., 1999), in a 7-wk-old calf (King, 1979), and in a 8-wk-old calf (Hawkins et al., 1986).

In the literature, there are no reports of abomasal displacement in bovine fetuses. The 2 reported here might be temporary abomasal displacements that occur in the last third of pregnancy or could be permanent and result in calves born with abomasal displacement.

\section{CONCLUSIONS}

Computed tomography is a reliable method for in situ examination of the fetal bovine stomach complex from the third month of gestation onward. It was able to detect an abnormal position of the abomasum during the final trimester of pregnancy. The individual stomach chambers had different patterns of volume increase throughout the gestation period. The monthly volume increase of stomach chambers was not uniform and varied throughout gestation. The maximum monthly increase of BW and stomach volume occurred between mo 4 and 5 of gestation, and the abomasum had another growth spurt between mo 5 and 6 . These 2 time points of gestation may be critical phases in fetal development during which intrauterine programming could lead to improved health and productivity of dairy calves in later life.

\section{ACKNOWLEDGMENTS}

The authors gratefully acknowledge the staff of the Teterower Fleisch GmbH (Teterow, Germany) for providing us with specimens to conduct this research. We also thank Bernd Linke and Viola Völzer (Güstrow, Germany) for providing us with excellent technical support in computed tomography.

\section{REFERENCES}

Becker, R., P. D. Arnold, and S. P. Marshall. 1951. Development of the bovine stomach during fetal life. J. Dairy Sci. 34:329-332.

Bell, A. 2006. Prenatal programming of postnatal productivity and health of livestock: A brief review. Anim. Prod. Sci. 46:725-732.

Bell, A. W., R. Slepetis, and U. Ehrhardt. 1995. Growth and accretion of energy and protein in the gravid uterus during late pregnancy in Holstein cows. J. Dairy Sci. 78:1954-1961.

Bertram, C. E., and M. A. Hanson. 2001. Animal models and programming of the metabolic syndrome Type 2 diabetes. Br. Med. Bull. 60:103-121.

Dhakal, K., C. Maltecca, J. Cassady, G. Baloche, C. Williams, and S. Washburn. 2013. Calf birth weight, gestation length, calving ease, and neonatal calf mortality in Holstein, Jersey, and crossbred cows in a pasture system. J. Dairy Sci. 96:690-698. 
Eley, R. M., W. Thatcher, F. W. Bazer, C. Wilcox, R. Becker, H. Head, and R. Adkinson. 1978. Development of the conceptus in the bovine. J. Dairy Sci. 61:467-473.

Flor, J., B. Linke, and P. Sanftleben. 2012. Möglichkeiten der Computertomographie zur Beurteilung der Mägenentwicklung beim Milchkalb. Zuchtungskunde 84:213-225.

Fowden, A. L., D. A. Giussani, and A. J. Forhead. 2006. Intrauterine programming of physiological systems: causes and consequences. Physiology (Bethesda) 21:29-37.

Fowden, A. L., J. Li, and A. J. Forhead. 1998. Glucocorticoids and the preparation for life after birth: are there long-term consequences of the life insurance? Proc. Nutr. Soc. 57:113-122.

Funston, R. N., D. M. Larson, and K. Vonnahme. 2010. Effects of maternal nutrition on conceptus growth and offspring performance: Implications for beef cattle production. J. Anim. Sci. 88:E205E215.

Godfrey, N. 1961. The functional development of the calf. I. Growth of the stomach of the calf. J. Agric. Sci. 57:173-175.

Habermehl, K. H. 1975. Die Altersbestimmung bei Haus- und Labortieren. Parey, Berlin, Germany.

Hales, C. N., and D. J. Barker. 1992. Type 2 (non-insulin-dependent) diabetes mellitus: The thrifty phenotype hypothesis. Diabetologia 35:595-601.

Hales, C. N., and D. J. Barker. 2001. The thrifty phenotype hypothesis. Br. Med. Bull. 60:5-20.

Hawkins, C. D., D. Fraser, J. Bolton, R. Wyburn, C. McGill, and B. Pearse. 1986. Left abomasal displacement and ulceration in an eight-week-old calf. Aust. Vet. J. 63:53-55.

Hofmann, R. R. 1989. Evolutionary steps of ecophysiological adaptation and diversification of ruminants: A comparative view of their digestive system. Oecologia 78:443-457.

Holland, M. D., and K. Odde. 1992. Factors affecting calf birth weight: A review. Theriogenology 38:769-798.

Johnson, E., D. Poppi, D. Farrell, and K. Lowe. 1996. Neonatal growth and development of the bovine stomach. Proc. Aust. Soc. Anim. Prod. 21:211-214.

Kano, Y., K. Fukaya, M. Asari, and Y. Eguchi. 1981. Studies on the development of the fetal and neonatal bovine stomach. Anat. Histol. Embryol. 10:264-274.

King, R. G. 1979. Left-displaced abomasum in a 48-day-old calf. Vet. Med. Small Anim. Clin. 74:1659-1660.

Langer, P. 1988. The Mammalian Herbivore Stomach: Comparative Anatomy, Function and Evolution. Gustav Fischer, Stuttgart, Germany

Lyne, A. 1960. Pre-natal growth of cattle. Proc. Aust. Soc. Anim. Prod. 3:153-161.

Michel, G. 1995. Vergleichende Embryologie der Haustiere: ein Lehrbuch auf funktioneller Grundlage. Fischer, Jena.

Moallem, U., D. Werner, H. Lehrer, M. Zachut, L. Livshitz, S. Yakoby, and A. Shamay. 2010. Long-term effects of ad libitum whole milk prior to weaning and prepubertal protein supplementation on skeletal growth rate and first-lactation milk production. J. Dairy Sci. 93:2639-2650.
Mueller, K., M. Merrall, and N. Sargisonm. 1999. Left abomasal displacement and ulceration with perforation of abdominal musculature in two calves. Vet. J. 157:95-97.

Oman, R. E., R. N. Streeter, E. J. Reppert, and C. Z. Chako. 2016. Left displacement of the abomasum in 4 beef calves. J. Vet. Intern. Med. 30:1376-1380.

Opsomer, G., M. Van Eetvelde, M. Kamal, and A. Van Soom. 2016 Epidemiological evidence for metabolic programming in dairy cattle. Reprod. Fertil. Dev. 29:52-57.

Prior, R. L., and D. Laster. 1979. Development of the bovine fetus. J. Anim. Sci. 48:1546-1553.

Roussel, A. J., N. D. Cohen, and R. N. Hooper. 2000. Abomasal displacement and volvulus in beef cattle: 19 cases (1988-1998). J. Am. Vet. Med. Assoc. 216:730-733.

Rüsse, I., and E. Grunert. 1993. Die wachsende Frucht. Altersbestimmung. Pages 52-53 in Tiergeburtshilfe. 4 ed. E. Grunert and K. Arbeiter, ed. P. Parey, Berlin, Germany.

Schnorr, B., and M. Kressin. 2011. Embryologie der Haustiere: Ein Kurzlehrbuch. 6 ed. Enke, Stuttgart, Germany

Schummer, A. 1932. Zur Formbildung und Lageveränderung des embryonalen Wiederkäuermagens. Anat. Embryol. (Berl.) 99:265303.

Silper, B. F., A. Lana, A. Carvalho, C. Ferreira, A. Franzoni, J. Lima, H. Saturnino, R. Reis, and S. Coelho. 2014. Effects of milk replacer feeding strategies on performance, ruminal development, and metabolism of dairy calves. J. Dairy Sci. 97:1016-1025.

Soberon, F., E. Raffrenato, R. W. Everett, and M. E. Van Amburgh 2012. Preweaning milk replacer intake and effects on long-term productivity of dairy calves. J. Dairy Sci. 95:783-793.

Soberon, F., and M. E. Van Amburgh. 2013. Lactation Biology Symposium: The effect of nutrient intake from milk or milk replacer of preweaned dairy calves on lactation milk yield as adults: A metaanalysis of current data. J. Anim. Sci. 91:706-712.

Szuba, Z., E. Kalisinska, and Z. Babula. 1988. Growth of body weight and length of bovine fetuses. Anat. Histol. Embryol. 17:53-59.

Tamate, H., A. D. McGilliard, N. L. Jacobson, and R. Getty. 1962 Effect of various dietaries on the anatomical development of the stomach in the calf. J. Dairy Sci. 45:408-420.

Vivo, J. M., A. Robina, S. Regodón, M. T. Guillen, A. Franco, and A. Mayoral. 1990. Histogenetic evolution of bovine gastric compartments during prenatal period. Histol. Histopathol. 5:461-476.

Wardrop, I., and J. Coombe. 1961. The development of rumen function in the lamb. Crop Pasture Sci. 12:661-680.

Warner, R., W. Flatt, and J. Loosli. 1956. Dietary factors influencing the development of the ruminant stomach. J. Agric. Food Chem. 4:788-792.

Witt, M., E. Walter, and W. Rappen. 1964. Untersuchungen über den Einfluß verschiedener Faktoren auf das Geburtsgewicht und die Beziehung zwischen dem Geburtsgewicht und dem 1/2-und 1-Jahresgewicht bei schwarzbunten Rindern. J. Anim. Breed. Genet. 80:3-24.

Zerbin, I., S. Lehner, and O. Distl. 2015. Genetics of bovine abomasa displacement. Vet. J. 204:17-22. 